International Scientific Organization

http://iscientific.org/

Chemistry International

www.bosaljournals.com/chemint/

\title{
Pharmacological activities of various phthalazine and phthalazinone derivatives
}

\author{
Mohammad Asif \\ Department of Pharmacy, GRD (P.G) Institute of Management \& Technology, Dehradun, (U.K), 248009, India \\ *Corresponding author's E. mail:aasif321@gmail.com
}

A R T I C L E I I N F

\section{Article type:}

Research article

Article history:

Received July 2018

Accepted October 2018

January 2019 Issue

Keywords:

Pthalazines

Phthalazinone

Heterocycle

Biological activities

\section{A B S T R A C T}

Various pthalazine derivatives have been synthesized and tested for their diverse biological activities. Pthalazine derivatives have been exhibited pharmacological activities like antitumor, PARP-1 inhibitors, antimicrobial, antivirus, antihistamine- $\mathrm{H} 1$, antiallergic rhinitis, antifungal, anti-inflammatory, antiproliferative, COX-2 inhibitor, LOX-5 inhibitor, antidiabetes, and other biological activities like imaging agent. Pthalazine derivatives were also used as agrochemicals and chemicals. Various synthetic aspects indicate that pthalazines derivatives are easy to synthesize which can produce a wide variety of activity.

(c) 2019 International Scientific Organization: All rights reserved.

Capsule Summary: Diverse pharmacological activities of pthalazine derivatives have been discussed and pthalazine derivatives offered promising activities as antitumor, PARP-1 inhibitors, antimicrobial, antivirus, antihistamine-H1, antiallergic rhinitis, antifungal, anti-inflammatory, anti-proliferative, COX-2 inhibitor, LOX-5 inhibitor and antidiabetes.

Cite This Article As:M. Asif.Pharmacological activities of various phthalazine and phthalazinone derivatives. Chemistry International 5(1) (2019) 97-108.

\section{INTRODUCTION}

Heterocyclic compounds containing nitrogen group have large area in nature, and their utilizationis becoming progressively important as biologically active pharmaceuticals, agrochemicals, and functional materials. In particular, hydrazine containing heterocyclic compounds has been considered of great importance on account of pharmacological properties and clinical applications (Turk et al., 2001). Phthalazine derivatives, like the other members of the isomeric benzodiazine series, have been applied as therapeutic agents due to their antimicrobial, antiepileptic, cardiotonic, vasorelaxant, antiinflammatory and analgesic properties (Tsoungas and Searcey, 2001; Sivakumar et al., 2002). Moreover, these of combined phthalazines have biological properties such as inhibition of p38MAPkinase
(Mavel et al., 2002) for selective binding of GABA receptor (Carling et al., 2004), antianxiety drug (Imamura et al., 2003), antitumor agent (Kim et al., 2004), and high affinity to the calcium channel (Lebsack et al., 2004). Phthalazine derivatives have been greatly used as therapeutic agents owing to their anti-proliferative, COX-2 inhibitor, LOX-5 inhibitor, antidiabetes, antiepileptic, cardiotonic, vasorelaxant, anti-inflammatory and other biological activities (Tsoungas and Searcey, 2001; Sivakumar et al., 2002; Coelho et al., 2004; Demirayak et al., 2004; Dogruer et al., 2004), and antimicrobial activity (Sonmez et al., 2006). Like azelastine, the phthalazine derivatives have antihistaminic effects in the treatment of allergic rhinitis (Tanizaki et al., 1992), and hydralazine is used as antihypertensive agent in the treatment of pulmonary hypertension (Groves et al., 1985; Keller et al., 1984). Pthalazines are synthetically versatile substrates and hence 
can be used for the synthesis of a large variety of heterocyclic compounds. Pthalazines occupy a distinct and unique place in our life. This hetero cyclic moiety has great biological and medicinal significance (Shu et al., 2017; Yuan et al., 2017; Wang et al., 2014; Rao et al., 2016). Encouraged by the diverse biological activities of pthalazine compounds, it was decided to prepare a new series of pthalazines derivatives. Some commercially used phthalazine derivatives are shown in Figure 1.

\section{Pharmacological activities}

The chemistry of phthalazine derivatives has been of increasing interest since many of these compounds have found many chemotherapeutic applications. A series of 2,4disubstituted phthalazinones were tested for their biological activities, like antiproliferation, inhibition against Aurora kinases and cell cycle effects. Among them, N-cyclohexyl-4((4-(1-methyl-1H-pyrazol-4-yl)-1-oxophthalazin-2(1H)-

yl)methyl)benzamide (1) exhibited the most potent antiproliferation against five carcinoma cell lines (HeLa, A549, HepG2, LoVo and HCT116 cells) with IC50 values in range of 2.2-4.6 $\mu \mathrm{M}$, while the $\mathrm{IC}_{50}$ value of standard drug VX680 was $8.5-15.3 \mu \mathrm{M}$. Moreover, Aurora kinase assays exhibited that a compound was potent inhibitor of AurA and AurB kinase with the $\mathrm{IC}_{50}$ values were 118 and $80 \mathrm{nM}$, respectively. This compound is a promising pan-Aurora kinase inhibitor for the potential treatment of cancer (Wang et al., 2018). Two series of 4-phenylphthalazin-1-ones and 4benzylphthalazin-1-ones compounds were tested as anti-lung adenocarcinoma agents with potential inhibitory activity against PARP-1. All the phthalazinones were tested for their anti-proliferative activity against A549 lung carcinoma cell line. Some phthalazinone compounds were showed significant cytotoxic activity against A549 cells at different concentrations $(0.1,1$ and $10 \mu \mathrm{M})$. These phthalazinones were also tested for their inhibitory activity towards PARP-1. One compound emerged as the most potent PARP-1 inhibitor with IC $_{50}$ value of $97 \mathrm{nM}$, compared to that of Olaparib $\left(\mathrm{IC}_{50}=139 \mathrm{nM}\right.$ ) (Almahli et al., 2018). Using a dengue replicon cell line-based test, 3-(dimethylamino)propyl(3-((4-(4fluorophenyl)-1-oxophthalazin-2(1H)-

yl)methyl)phenyl)carbamate (2) act as a potent DENV-2 inhibitor, with an $\mathrm{IC}_{50}$ value of $0.64 \mu \mathrm{M}$. A series of phthalazinones based on hit 2 were tested for their in vitro anti-DENV activity and cytotoxicity. The subsequent structure activity relationship (SAR) study and optimization led to the discovery of the most promising compound, which exhibited potent anti-DENV-2 activity, with low $\mathrm{IC}_{50}$ value against DENV-2 RNA replication of $0.13 \mu \mathrm{M}$ and high selectivity (SI $=89.2$ ) with suitable pharmacokinetics profile (Lu et al., 2018).

During liver development, nonpolarized hepatic progenitor cells distinguish into mature hepatocytes with different polarity. This polarity is crucial for sustaining the intrinsic properties of hepatocytes. The balance between the epithelial-mesenchymal transition (EMT) and mesenchymal- epithelial transition (MET) acts a decisive role in differentiation of polarized hepatocytes. The phthalazinone pyrazole (PP), a selective inhibitor of Aurora-A kinase (Aurora-A), suppressed the EMT during the differentiation of hepatocyte-like cells (HLCs) from human embryonic stem cells. The differentiated HLCs treated with PP at the hepatoblast stage exhibited enhanced hepatic morphology and functions, mainly with regard to the expression of drug metabolizing enzymes. The regulatory role of the EMT on in vitro hepatic maturation, suggested that inhibition of the EMT may drive transformation of hepatoblast cells into mature and polarized HLCs (Choi et al., 2018). Potency of amidecontaining phthalazinone $\mathrm{H}_{1}$ histamine receptor antagonists is described. Three analogues were equipotent with azelastine and were longer-acting in vitro. Amide derivative had low oral bioavailability, low brain-penetration, high metabolic clearance, and long duration of action in vivo, and it was suitable for once-daily dosing intranasally, with a predicted dose for humans of approximately $0.5 \mathrm{mg} / \mathrm{day}$ (Procopiou et al., 2017). Some phthalazinones were shown to be potent enhancers of antifungal activity of fluconazole against Candida albicans. Some even more potent analogues of these compounds were identified, some with $\mathrm{EC}_{50}$ as low as $1 \mathrm{nM}$, against $C$. albicans. The compounds exhibited pharmacological synergy $(\mathrm{FIC}<0.5)$ with fluconazole. The compounds were also shown to enhance the antifungal activity of isavuconazole, an antifungal. Phthalazinone were shown to be active against several resistant clinical isolates of C. albicans (Mood et al., 2017).

Phthalazinone derivatives were designed as optical probes for one- and two-photon fluorescence microscopy imaging. The design strategy involves stepwise extension and modification of pyridazinone by 1) expansion of pyridazinone to phthalazinone, a larger conjugated system, as the electron acceptor, 2) coupling of electron-donating aromatic groups like $\mathrm{N}, \mathrm{N}$-diethylamino-phenyl, thienyl, naphthyl, and quinolyl to the phthalazinone, and 3) anchoring of an alkyl chain to the phthalazinone with various terminal substituents such as triphenylphosphonio, morpholino, triethylammonio, N-methylimidazolio, pyrrolidino, and piperidino. The desired fluorescent probes were prepared by two different routes in considerable yields. Some phthalazinones were synthesized and their photophysical properties were measured. These compounds showed excellent performance in two-photon microscopic imaging of mouse brain slices (Zhu et al., 2016). A series of proteasome inhibitors using pyridazinone as initial scaffold, and extended the structure with rational design by computer aided drug design (CADD). Two different synthetic routes were explored and the biological evaluation of the phthalazinone derivatives was tested. The electron positive triphenylphosphine group was first introduced in the structure of proteasome inhibitors and potent inhibition was achieved (Yang et al., 2016). The phthalazinethione has been synthesized and behavior towards hydrazine hydrate, oxidizing agent and ethyl chloroacetate has been tested. 


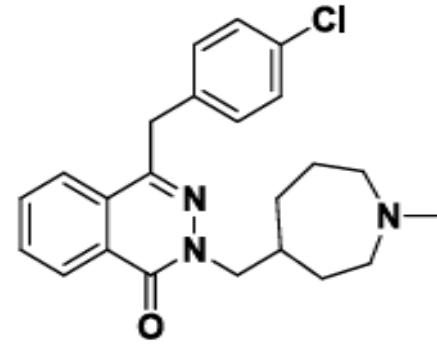

Azelastin

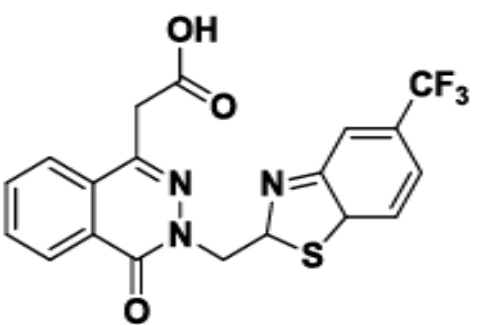

Zopolrestat<smiles>Nc1cccc2c(=O)[nH]nc(O)c12</smiles>

Luminal<smiles>NNc1nncc2ccccc12</smiles>

Hydrazine

Fig. 1: Some commercially used phthalazine drugs

The synthesized compounds were tested for antimicrobial, cytotoxic, and antioxidant activities. Some of the compounds were showed very strong cytotoxic activity with respect to the standard (Marzouk et al., 2016). The study aims to synthesize phthalazine derivatives and to test their antiinflammatory and anti-proliferative activities. Some compounds, showed significant anti-inflammatory activity comparable with that of the standard drug etoricoxib in the carrageenan-induced rat paw edema model. Some compounds showed moderate sensitivity toward the renal cancer cell line UO-31 (Hameed et al., 2016).

The design and synthesize a series of Non-steroidal anti-inflammatory drugs (NSAIDs) with minimal gastric complications. A series of 4-(3,4-dimethylphenyl)-2(1H)phthalazinone derivatives (3) were synthesized and tested for their in vivo anti-inflammatory activity. The compounds that showed powerful anti-inflammatory activities were assessed for their in vitro COX-1/COX-2 inhibitory activity and their in vivo ulcerogenic profile. The interaction between the designated compounds and the binding pocket of the COX-2 enzyme was predicted by molecular docking stimulation. Some compounds, showed significant antiinflammatory activities compared to standard drug celecoxib. Few compounds were the most potent and selective COX-2 inhibitors. Moreover, all the compounds showed higher gastric safety profile compared to celecoxib and one compound displayed the highest safety profile. Among the tested compounds, one compound displayed the highest antiinflammatory activity and COX-2 selectivity with minimal ulcer score. Some compounds were the most potent inhibitors to COX-2 and were inactive to COX-1. The screened compounds showed better ulcer protection and less gastric lesion compared to celecoxib. One compound was the most promising candidate with more gastric safety (Hasabelnaby et al., 2015). The androgen receptor (AR) plays important roles in multiple physiological functions, including differentiation, growth, and maintenance of male reproductive organs, and also has effects on hair and skin. The synthesis of nonsteroidal AR antagonists having a 4benzyl-1-(2H)-phthalazinone skeleton, among the synthesized compounds, with two ortho-substituents on the phenyl group potently inhibited SC-3 cell proliferation (IC50: $0.18 \mu \mathrm{M}$ ) and showed high wt AR-binding affinity (IC50: 10.9 $\mu \mathrm{M})$, comparable to that of hydroxyflutamide. Compound also inhibited proliferation of LNCaP cells containing T877Amutated AR. The phthalazinone derivatives may be useful for testing clinical applications of AR antagonists (Inoue et al., 2015).

With the aim to discover orally active small molecules that stimulate glucose uptake, high throughput screening of a library of 5000 drug-like compounds was conducted in differentiated skeletal muscle cells in presence of insulin. N-Substituted phthalazinone acetamide (4) was identified as a potential glucose uptake modulator. Several novel derivatives were synthesized to establish structure activity relationships. Identified lead thiazolylphthalazinone acetamide (7114863) increased glucose uptake $\left(\mathrm{EC}_{50}\right.$ of $\left.0.07 \pm 0.02 \mu \mathrm{M}\right)$ in differentiated skeletal muscle cells in presence of insulin. The 7114863 was superior to rosiglitazone without inducing PPAR- $\gamma$ agonist activity thus making it a very interesting scaffold (Agrawal et al., 2013). The 4-(4-bromophenyl)phthalazine derivatives (5) connected via an alkyl spacer to amine or N-substituted piperazine were synthesized as promising $\alpha$-adrenoceptor antagonists. The phthalazine derivatives were displayed significant $\alpha$-blocking activity (Khalil et al., 2013). Various polysubstituted phthalazinone derivatives were tested for their antifungal activity against a panel of pathogenic and clinically important yeasts and filamentous fungi. Among them, the compound 4-(4-chlorobenzyl)-2-methylphthalazin$1(2 \mathrm{H})$-one (6) exhibited a remarkable antifungal activity against standardised strains of dermatophytes and Cryptococcus neoformans, as well as against some clinical isolates. The compound 5 revealed its conformational and electronic characteristics, providing us with useful data for the future design of antifungal analogues (Derita et al., 2013).

The design and synthesis of pyridazinone and phthalazinone derivatives were tested on a panel of four kinases in order to evaluate their activity and potential selectivity. The promising compounds were tested on four cancer cell lines to examine cytotoxic effects. The compounds inhibited DYRK1A and GSK3 with different activity. The 
findings suggest that pyridazinone and phthalazinone scaffolds are interesting starting points for design of potent GSK3 and DYRK1A inhibitors (Elagawany et al., 2013). Poly(phthalazinone-ether-sulfone) (PPES) polymer is a relatively newly developed material with a bis(4-fluorodiphenyl) sulfone group. The formation of the PPES membrane by wet-phase inversion can proceed according to a slow or fast gelation method. The resulting membrane morphology was tested using both optical and scanning electron micrography. The effects of PPES concentration and two additives, polyvinylpyrrolidone (PVP) and oxalic acid $(\mathrm{OA})$, on the apparent viscosity and gelation rate of PPESK/NMP solutions and membrane performance have also been tested. The results provide a fundamental insight in this novel copolymer, useful in future applications, especially in the membrane formation process (Qin et al., 2013).

Cryptosporidium parvum (Cp) is a potential biowarfare agent and major cause of diarrhea and malnutrition. This protozoan parasite relies on inosine 5'monophosphate dehydrogenase (IMPDH) for the production of guanine nucleotides. A CpIMPDH-selective $\mathrm{N}$-aryl-3,4dihydro-3-methyl-4-oxo-1-phthalazineacetamide inhibitor was identified. Herein we report a SAR study for the phthalazinone-based series that resulted in the discovery of benzofuranamide analogs that exhibit low nanomolar inhibition of CPIMPDH. The antiparasitic activity of select analogs in a Toxoplasma gondii model of $\mathrm{C}$. parvum infection is also presented (Johnson et al., 2013).

The 5-Aza, 6-aza, 7-aza and 8-aza-phthalazinone, and 5,8-diazaphthalazinone (8a-c) templates were synthesized. All mono-azaphthalazinone series had higher affinity (pK(i)) for the human $\mathrm{H}(1)$ receptor than azelastine, but were not as potent as the parent non-aza phthalazinone. The 5,8diazaphthalazinone was equipotent with azelastine. The least potent series were the 7-azaphthalazinones, whereas the 5azaphthalazinones were the most lipophilic. The more hydrophilic series were the 8-aza series. Replacement of the $\mathrm{N}$-methyl substituent on the pyrrolidine with the n-butyl group caused an increase in potency $(\mathrm{pA}(2))$ and a corresponding increase in lipophilicity. Introduction of a $\beta$ ether oxygen in the n-butyl analogues (2-methoxyethyl group) decreased the $\mathrm{H}(1) \mathrm{pA}(2)$ slightly, and increased the selectivity against hERG. The duration of action in vitro was longer in the 6-azaphthalazinone series. The more potent and selective 6-azaphthalazinone core was used to append an $\mathrm{H}(3)$ receptor antagonist fragment, and to convert the series into the long acting single-ligand, dual $\mathrm{H}(1) \mathrm{H}(3)$ receptor antagonist (Procopiou et al., 2012).

The bradykinin B1 receptor is rapidly induced upon tissue injury and inflammation, stimulating the production of inflammatory mediators resulting in plasma extravasation, leukocyte trafficking, edema, and pain. A series of potent phthalazinone B1 antagonists, successfully replaced a sulfonamide acceptor with a cyclic carbonyl unit. SAR studies revealed compounds with subnanomolar B1 binding affinity. These compounds exhibited high oral bioavailability and potent activity in a rabbit biochemical challenge pharmacodynamic study (Biswas et al., 2011).

A series of potent phthalazinone-based human $\mathrm{H}(1)$ and $H(3)$ bivalent histamine receptor antagonists, suitable for the treatment of allergic rhinitis were identified. Blockade of $\mathrm{H}(3)$ receptors is to improve efficacy on nasal congestion (allergic rhinitis) that is currently not treated by current antihistamines. Two phthalazinone analogues had slightly lower $\mathrm{H}(1)$ and $\mathrm{H}(3)$ potency than azelastine. One compound had longer duration of action than azelastine, low brain penetration, and low oral bioavailability, should limit the potential of engaging CNS-related side-effects associated with H(1) or H(3) antagonism (Procopiou et al., 2011). Cultures of Aspergillus niger NRRL-599 in fluid Sabouraud medium were grown with phthalazine for 7 days. Metabolite of phthalazine was oxidized to 1-phthalazinone (Sutherland et al., 2011). The inhibition of Aurora kinases in order to arrest mitosis and subsequently inhibit tumor growth via apoptosis of proliferating cells. A class of Aurora kinase inhibitors based upon a phthalazinone-pyrazole scaffold resulted in a potent Aurora-A selective series of compounds (typically $>1000$-fold selectivity over Aurora-B) that display good pharmacological profiles with significantly improved oral bioavailability compared to the Aurora inhibitor VX-680 (Prime et al., 2011). Inhibitors of PDE-4 are an important class of antiinflammatory drug that act by inhibiting the production of proinflammatory cytokines, including tumor necrosis factoralpha (TNF- $\alpha)$ and tested a series of 2substituted phthalazinone derivatives as PDE-4 inhibitors. SAR studies led to the recognition of benzylaminesubstituted phthalazinones as potent PDE-4 inhibitors that also suppressed TNF- $\alpha$ production by whole rat blood cells.

The most potent of these, when topically used, were effective in a mouse model of dermatitis (Kagayama et al., 2009). A meroterpenoid, azamerone, was isolated from the saline culture of a marine-derived bacterium related to the genus Streptomyces. Azamerone is composed of a chloropyranophthalazinone core with a 3-chloro-6-hydroxy2,2,6-trimethylcyclohexylmethyl side chain (Cho et al., 2006).

The 2-(5-Chloro-1,3-diphenyl-1H-pyrazol-4ylmethylene)-malononitrile compounds (9) showed a moderate molluscicidal activity towards Biomphalaria alexandrina snails (Abdelrazek et al., 2006). A series of phthalazinone derivatives were synthesized and their vasorelaxant activity was measured on isolated rat aorta rings pre-contracted with phenylephrine $(10(-5) \mathrm{M})$. Some phthalazinones attained, the total relaxation of the organ at micromolar concentrations. For the most potent compound $\left(E C_{50}=0.43\right.$ microM $)$ the affinities for $\alpha_{1 \mathrm{~A}}, \alpha_{1 \mathrm{~B}}$ and $\alpha_{1 \mathrm{D}}$ adrenergic sub-receptors were determined (del Olmo et al., 2006). Discovery of poly(ADP-ribose)polymerase-1 (PARP-1) inhibitors based on a phthalazinone scaffold. Subsequent optimisation of inhibitory activity, metabolic stability and pharmacokinetic parameters has led to a series of metasubstituted 4-benzyl-2H-phthalazin-1-one PARP-1 inhibitors which retain low nM cellular activity and show good stability in vivo in cell based models (Cockcroft et al., 2006). 
<smiles>Cn1cc(-c2nn(Cc3ccc(C(=O)NC4CCCCC4)cc3)c(=O)c3ccccc23)cn1</smiles>

1<smiles>Cc1ccc(-c2n[nH]c(=O)c3ccccc23)cc1C</smiles>

3<smiles>Cn1nc(CC(=O)Nc2ccccc2)c2ccccc2c1=O</smiles>

7

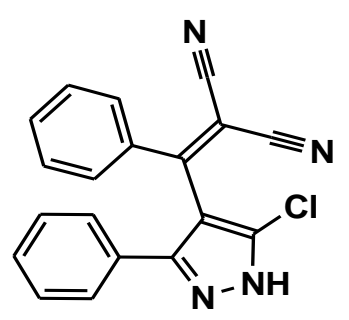

9

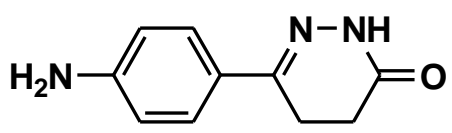

12<smiles>NC(=O)n1ncc2ccccc2c1=O</smiles>

4

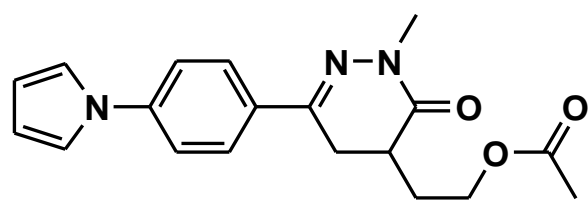

10

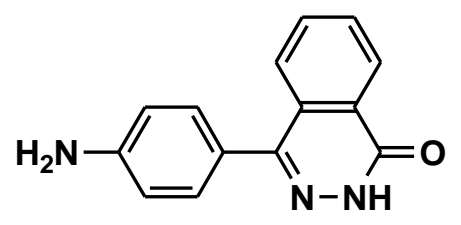

13

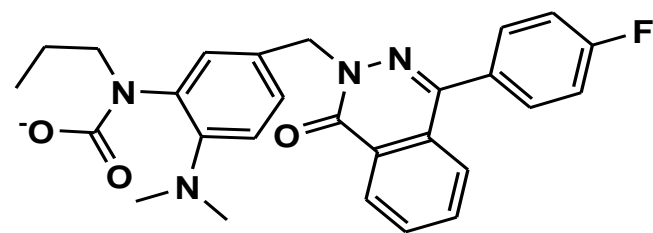

2<smiles>Brc1ccc(-c2nncc3ccccc23)cc1</smiles>

5<smiles>O=c1nncc2cc[nH]cc1-2</smiles>

$8 \mathrm{~b}$

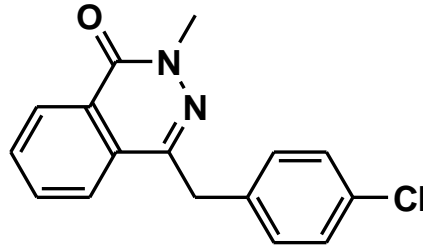

6<smiles>O=c1nncc2[nH]cccc1-2</smiles>

$8 c$<smiles>N=C(NC(=O)c1ccccc1C(=O)N1C(=O)C(=C2C=CC=CC2)N=C1c1ccccc1)c1ccccc1</smiles>

15<smiles>Cn1nc(-c2ccc(-n3cccc3)cc2)c2ccccc2c1=O</smiles>

11

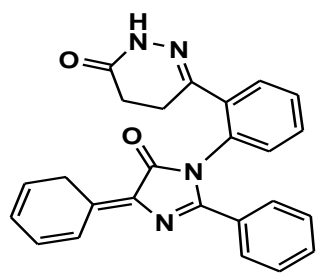

14

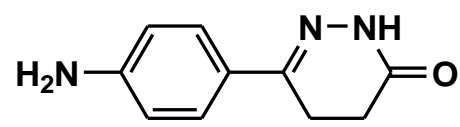

16 


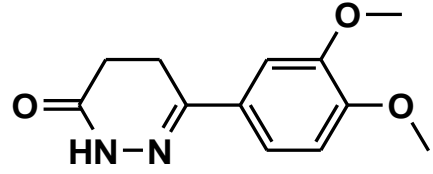

17

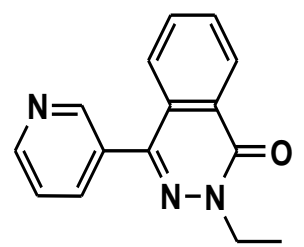

20

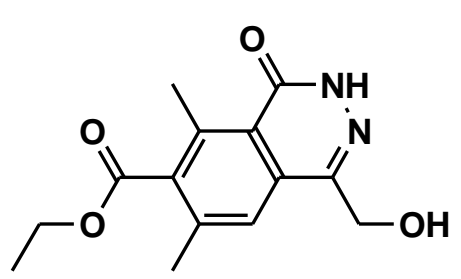<smiles>O=c1[nH]nc(CO)c2ccccc12</smiles>

EG-626<smiles>COc1ccc(-c2n[nH]c(=O)c3ccccc23)cc1OC</smiles>

18

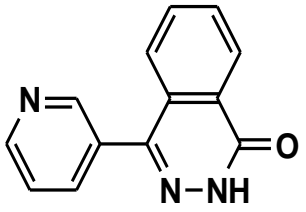

19

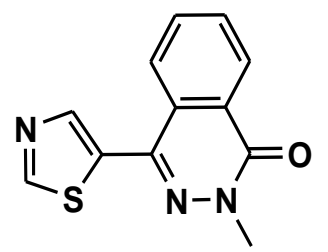

21<smiles>O=c1c2ccccc2cnn1CCn1ccnc1</smiles>

22

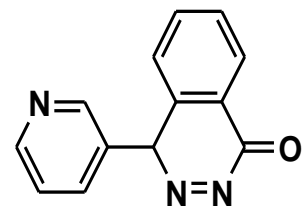

23
Some 2-nonsubstituted/2-methyl-/2-(2-acetyloxyethyl)-6[4-(substituted pyrrol-1-yl)phenyl]-4,5-dihydro-3(2H)pyridazinones (10) and 2-nonsubstituted/2-methyl- 4-[4(substituted pyrrol-1-yl)phenyl]-1(2H)phthalazinones derivatives (11) were synthesised with corresponding 2-substituted/nonsubstituted 6-(4'aminophenyl)-4,5-dihydro-3(2H)-pyridazinone (12) or 2substituted/nonsubstituted-4-(4'-aminophenyl)-(2H)-

phthalazinone (13) were tested for antihypertensive activities in both in vitro and in vivo models and some derivatives showed appreciable activity (Demirayak et al., 2004).

The 6-[(4-arylidene-2-phenyl-5-oxoimidazolin-1yl)phenyl]-4,5-dihydro-3(2H)-pyridazinone (14) and 4-[(4arylidene-2-phenyl-5-oxoimidazolin-1-yl)phenyl]-1(2H)-

phthalazinone derivatives (15) were prepared by reacting 6(4-aminophenyl)-4,5-dihydro-3(2H)-pyridazinone or 4-(4aminophenyl)-1(2H)-phthalazinone (16) compound with different 4-arylidene-2-phenyl-5(4H)-oxazolone derivatives and tested for vasodilator activities in both in vitro and in vivo model. Some pyridazinone derivatives showed appreciable activity (Demirayak et al., 2004).

A series of 5-[4-[2-[substituted phthalazinones-2(or 4)yl] ethoxy]phenylmethyl]thiazolidine-2,4-diones and 5-[4[2-[2,3-benzoxazine-4-one-2-

yl] ethoxy]phenylmethyl] thiazolidine-2,4-diones and their plasma glucose and plasma triglyceride lowering activity in mice. In vitro PPAR $\gamma$ trans activation assay was performed in
HEK 293T cells. In vitro and in vivo pharmacological studies showed that the phthalazinone analogue has better activity. One compound (PHT46) is the best compound in this series, showed better in vitro PPAR $\gamma$ trans-activation potential than troglitazone and pioglitazone. In insulin resistant mice, PHT46 showed better plasma glucose and triglyceride lowering activity than the standard drugs. Subchronic toxicity study in Wistar rats did not show any treatmentrelated adverse effect (Madhavan et al., 2001).

A number of 6-(3,4-dimethoxyphenyl)-4,5-dihydro2H-pyridazin-3-ones (17) and a series of 4-(3,4dimethoxyphenyl)-2H-phthalazin-1-ones (18) were prepared and tested on the cGMP-inhibited PDE-3 and CAMPspecific PDE-4 enzymes. All tested compounds were found to specifically inhibit PDE-4 except for few pyridazinone, which showed moderate PDE-4 $\left(\mathrm{pIC}_{50}=6.5\right)$ as well as PDE-3 $\left(\mathrm{pIC}_{50}=6.6\right)$ inhibitory activity. In both the pyridazinone and phthlazinone series it was found that $\mathrm{N}$-substitution is beneficial for PDE-4 inhibition, whereas in the pyridazinone series it also accounts for PDE4 selectivity. In the phthalazinone series, the cis-4a,5,6,7,8,8ahexahydrophthalazinones and their corresponding 4a,5,8,8atetrahydro analogues showed potent PDE-4 inhibitory potency (Van der Mey et al., 2001).

A series of 4-(3-pyridyl)-1(2H)phthalazinone derivatives (19) which possess dual activities of thromboxane A2 (TXA2) synthetase inhibition and bronchodilation, while the length and the bulk of 2-alkyl 
substituents had no influence on either activity, the 2substituents with polar groups reduced bronchodilatory activity. Furthermore, heteroaromatic nuclei into the 4position of the phthalazinone and found that 1-imidazolyl and 5-thiazolyl derivatives were as active as the parent 3pyridyl compound. The heteroaromatic nuclei at the 4position of phthalazinones is play a vital role in TXA2 synthetase inhibition. The hydrophobicity of the compounds was found to exert a marked influence on bronchodilatory activity. The selection of 2-ethyl-4-(3-pyridyl)-1(2H)phthalazinone (KK-505) (20) and 2-methyl-4-(5-thiazolyl)$1(2 \mathrm{H})$-phthalazinone (KK-562) (21) is for further studies. Although their precise mechanism of action remains unclear, this series of novel phthalazinone derivatives represents a new class of antiasthma agents with dual activities (Yamaguchi et al., 1993). Various 4-substituted 2-[omega-(1imidazolyl)alkyl]-1(2H)-phthalazinones (22) were synthesized to develop agents possessing both thromboxane A2 synthetase inhibitory and bronchodilatory activities. Both activities were slightly dependent on the length of the 2substituents and largely affected by the nature of the 4substituents. Compounds bearing phenyl and thienyl groups exhibited relatively high and well-rounded activities. Some compounds were found to be the most effective agents. The 4-(3-Pyridyl)phthalazinone (23) was of particular interest because of unexpectedly high in vivo activities in spite of an absence of significant in vitro activities (Yamaguchi et al., 1993).

In female NMRI mice, the phthalazinone azelastine was used orally once daily over 7 days. The drug influenced the epidermal thymidine triphosphate and amino acid incorporation rates at doses between 1 and $5 \mathrm{mg} / \mathrm{kg}$. In control mice, an epidermal hyperproliferation induced by abrasion of superficial epidermal layers was described by enhanced prostaglandin (PGs) and leukotriene (LTs) concentrations in epidermal homogenate, an increase in thymidine triphosphate and amino acid incorporation and an increase in epidermal thickness. In mice treated with 1 $\mathrm{mg} / \mathrm{kg}$ azelastine $\mathrm{HCl}$, this epidermal reaction was changed. Compared to controls, the increase in LTs concentration was diminished, and that of PGs was enhanced. The incorporation of thymidine triphosphate and of amino acids as well as the epidermal thickness and the ratio cell count/epidermal thickness were increased in irritated skin of azelastinetreated mice. The azelastine influences the epidermal metabolism in irritated and unirritated skin. Therefore, a beneficial role of this phthalazinone in the treatment of psoriasis and related skin disorders seems to be possible (Kietzmann et al., 1992).

The 4-substituted phthalazinone derivatives with possible antibacterial activity (Kassem et al., 1989) was reported and platelet aggregation of 2-phenyl-1(2H)phthalazinonederivatives also revealed inhibitory effects (Sugimoto et al., 1985).

7-Ethoxycarbonyl-4-hydroxymethyl-6,8-dimethyl$1(2 \mathrm{H})$-phthalazinone (EG 626) $(0.3-3 \mathrm{mg} / \mathrm{kg}$ i.v.), a cyclic AMP PDE inhibitor, increased femoral, renal, coronary, carotid, vertebral and sagittal blood flows in anesthetized dogs. Systolic tension in left ventricular wall, heart rate and cardiac output also increased. These properties of EG 626 resembled those of papaverine (0.1-1 $\mathrm{mg} / \mathrm{kg}$ i.v.). The heart rate increasing activity of EG 626 was less than that of papaverine at equipotent does on the vasodilator actions. In the isolated right atria of guinea pigs, EG 626 was more selective for increasing contractility than for increasing the sinus rate. The cardiovascular actions of EG 626 were also examined in perfused vascular beds and papillary muscle preparations of dogs. An i.v. infusion of EG 626 or papaverine $(0.3 \mathrm{mg} / \mathrm{kg} / \mathrm{min})$ enhanced the increasing action of isoprenaline on left ventricular systolic pressure and coronary sinus outflow. The vasodilator effect of EG 626 was no suppressed by atropine, propranolol nor clemastine, and the inotropic action was not modified by pindolol. The EG 626 may be a useful vasodilator with a cardiotonic activity but with less potency to cause tachycardia than papaverine (Furuta et al., 1985). 7-(Ethoxycarbonyl)-6,8-dimethyl-2phenyl-1 $(2 \mathrm{H})$-phthalazinone derivatives were synthesized for tested their inhibitory effects on platelet aggregation. All synthesized compounds were showed no appreciable effect on platelet aggregation induced by adenosine diphosphate, but most of them inhibited effectively the arachidonic acid (AA) induced platelet aggregation. The 2-phenyl derivatives, and ortho-substituted 2-phenyl derivatives showed the most potent inhibition of all compounds (Sugimoto et al., 1984). Antihypersensitivity agent is a 4-(p-chlorobenzyl)-2-[Nmethyl-perhydroazepinyl-(4)]-1-(2H)-

phthalazinone hydrochloride (azelastine) (Inoue. 1983). Effects of 7-ethoxycarbonyl-6,8-dimethyl-4-hydroxymethyl$1(2 \mathrm{H})$-phthalazinone (EG626) on the spinal trigeminal nucleus (STN), ventral posteromedial nucleus (VPM), and sensory cortex were examined in cats anesthetized with $\alpha$ chloralose in comparison with the effects of morphine. EG626 produced a dose-dependent inhibition of the polysynaptic components of the cortical field potentials upon VPM stimulation and either facilitatory or inhibitory effects on the polysynaptic components of the VPM field potential upon stimulation of the medial lemniscus, while the drug failed to affect the STN field potential with trigeminal nerve stimulation. Morphine inhibited the postsynaptic components of the STN field potentials and to a lesser extent, the polysynaptic components of the cortical field potential; and the effects of morphine on the VPM field potential were similar to those seen with EG626. Pretreatment of the animal with naloxone antagonized the facilitatory effect on the VPM field potentials produced by morphine, but not those by EG626. Morphine and EG626 induced either a prolonged increase in the blood flow or transient increase followed by a decrease in the blood flow in the VPM. These results suggest that EG626 may impair the polysynaptic transmission and/or neuron excitability in the sensory cortex and the VPM at least partly due to the change in blood flow there as does morphine. Unlike morphine, however, EG626 did not produce any obvious effect on the STN (Azuma et al., 1982). The 7-ethoxycarbonyl-4-hydroxymethyl-6,8-dimethyl-1(2H)- 
phthalazinone (EG 626) is an antiatherosclerotic agents (Ishikawa et al., 1980). The 7-ethoxycarbonyl-6, 8-dimethyl4-hydroxymethyl-1 (2H)-phthalazinone (EG-626), was found to be a considerably potent cardiotonic agent. It produced both the positive chronotropic and inotropic actions in the guinea pig heart muscle. Positive inotropic action of isoproterenol was potentiated by EG-626 at the concentration which did not produce a substantial positive inotropic action by itself. Cardiac action potential was not modified by EG-626 at concentrations sufficient to produce positive inotropic actions. EG-626 has a strong activity to produce slow responses in the depolarized myocardium, indicating that it can increase the density of the slow channels. The increase in the density of the slow channel may play an vital role in the positive inotropic action of EG-626. The increase in the intracellular cyclic AMP due to the PDE inhibition is tentatively most likely to be the cause of the EG626 induced in the density of the slow channels (Shigenobu et al., 1980).

Anti-aggregating activity of 7-ethoxycarbonyl-6,8dimethyl-4-hydroxymethyl-1(2H)-phthalazinone (EG 626) was tested using rabbit platelets in vitro. EG-626 alone, prevented platelet aggregation induced by ADP, as did PGI2, papaverine and dipyridamole. EG-626 alone also inhibited platelet aggregation induced by collagen and arachidonic acid. ID50s of these agents in ADP-induced aggregation were 7-9 nM for PGI2, 223 microM for EG-626, 266 $\mu \mathrm{M}$ for papaverine and $957 \mu \mathrm{M}$ for dipyridamole. When EG-626 was used in combination with PGI2, a threshold dose $(50 \mu \mathrm{M})$ of EG-626 potentiated the anti-aggregation effect of subthreshold dose (3 nM) of PGI2 upto 100\% inhibition in collagen-induced platelet aggregation. The marked potentiating effect of EG-626 was accompanied by an accumulation of cyclic AMP in the platelets. These effects might be due to inhibition of PDE. Papaverine and dipyridamole, other PDE inhibitors, also potentiated the antiaggregating effetcs of PGI2. The most effective combination of PGI2 and EG-626 to induce 50\% inhibition was obtained with $20 \%$ of ID50 of each agent, whereas that of PGI2 and papaverine or dipyridamole was 39 or $41 \%$, respectively (Tanaka et al., 1980). The 4-hydroxymethyl-1(2H)phthalazinone derivatives were exhibited as antiatherosclerotic agents (Eguchi et al., 1980).

The metabolic fate of a antiallergic agent, azelastine (4-(p-chlorobenzyl)-2-[N-methylperhydroazepinyl-(4)]-1-

$(2 \mathrm{H})$-phthalazinonehydrochloride) in rats and guinea pigs was tested using its 14C-labelled compound. The blood level of radioactivity reached the maximum at 1-1.5 hr after oral use, indicating the rapid absorption of the drug from gastrointestinal tract. A high concentration of radioactivity was detected in the lung of both species following either oral or i.v administration. The major pathway of excretion of radioactivity was by way into feces, in both species. The radioactivity excreted in feces was attributable to that which was excreted in bile and exsorbed into gastrointegtinal tract. When the drug was given to pregnant rats, the concentration of radioactivity in the fetus was significantly lower than those in placenta and uterus, indicating the limited placental transfer of the drug. The successive oral administration of the drug in lower doses exerted no effect on the activity of microsomal drug-metabolizing enzymes of rat liver, while in higher doses, had a slight effect (Tatsumi et al., 1980).

7-Ethoxycarbonyl-6,8-dimethyl-4-hydroxymethyl-

$1(2 \mathrm{H})$-phthalazinone (EG-626) was reported as an antagonist of thromboxane (TX) A2 in the contraction of rabbit aorta. It was observed that EG-626 did inhibit the contraction of superfused rabbit aorta, but also did inhibit that of rabbit coeliac artery, rat stomach strip and rat colon induced by TXA2, PG endoperoxides, angiotensin II and PGF2 $\alpha$ in nonspecific manner. EG-626 had no effect on the biosynthesis of PG endoperoxides as well as TXA2. Thes EG-626 is not a TXA2 antagonist, but has a general inhibitory effect on the smooth muscles. This inhibitory effect of EG-626 may be explained by the inhibition of PDE (Harada et al., 1979).

Anti-allergic properties of 4-(p-chlorobenzyl)-2[Nmethyl-perhydroazepinyl-(4)]-1-(2H)-

phthalazinone hydrochloride (azelastine, A-5610) were tested focusing the most attention on its decongestive effect. Intravenous injection of azelastine into anesthetized dogs with doses more than $0.1 \mathrm{mg} / \mathrm{kg}$ prevented the changes in nasal impedance provoked by histamine sprayed into the nasal cavity. When azelastine was given orally, the minimum effective dose to abolish the impedance reduction due to histamine was $2 \mathrm{mg} / \mathrm{kg}$, in the case of cleamastine the same dose was required. Histamine release from the rat mesentery pieces by the condensation product of $\mathrm{N}$-methylhomoanisylamine formaldehyde $(0.005 \%)$ was inhibited almost completely by pretreatment with azelastine at the concentrations of $10(-4)$ to $10(-3) \mathrm{g} / \mathrm{ml}$, and in those concentrations azelastine alone released histamine scarcely. When $5 \mathrm{mg} / \mathrm{kg}$ of azelastine was given i.v. to rabbits, the characteristic changes in EEG-a high-voltage low-frequency pattern-persisted more than $1 \mathrm{~h}$, but not the least inhibition in arousal response was noted. With the dose of $0.5 \mathrm{mg} / \mathrm{kg}$, diphenhydramine impaired arousal response and slow waves with high amplitude dominantly appeared in EEG (Tasaka and Akagi, 1979).

\section{CONCLUSIONS}

In conclusion, various series of pthalazine derivatives were synthesized, characterized and their pharmacological and chemical activities have been evaluated. It was observed that pthalazine derivatives could possibly be used as antitumor, PARP-1 inhibitors, antimicrobial, antivirus, antihistamine, antiallergic rhinitis, antifungal, anti-inflammatory, antiproliferative and antidiabetes agents.

\section{ACKNOWLEDGEMENTS}

Authors are thankful to my research supervisors for providing us required facilities and motivation for completion of the work. 


\section{REFERENCES}

Abdelrazek, F.M., Michael, F.A., Mohamed, A.E., 2006. Synthesis and molluscicidal activity of some 1,3,4-triaryl5-chloropyrazole, pyrazolylphthalazine and pyrano[2,3-d]thiazole derivatives. Arch Pharm (Weinheim) 339(6), 305-312.

Agrawal, M., Kharkar, P., Moghe, S., Mahajan, T., Deka, V., Thakkar, C., Nair, A., Mehta, C., Bose, J., KulkarniAlmeida, A., Bhedi, $\quad$ D., Vishwakarma, R.A., 2013. Discovery of thiazolyl-phthalazinone acetamides as potent glucose uptake activators via high-throughput screening. Bioorganic \& Medicinal Chemistry Letters 23(20), 5740-5743.

Almahli, H., Hadchity, E., Jaballah, M.Y., Daher, R., Ghabbour, H.A., Kabil, M.M., Al-Shakliah, N.S., Eldehna, W.M., 2018. Development of novel synthesized phthalazinone-based PARP-1 inhibitors with apoptosis inducing mechanism in lung cancer. Bioorganic Chemistry 77,443-456.

Azuma, H., Takashima, Y., Ishikawa, M., Sasa, M., Fujiwara, M., 1982. Effects of 7-ethoxycarbonyl-6,8-dimethyl-4hydroxymethyl-1(2H)-phthalazinone (EG626) on the spinal trigeminal nucleus, ventral posteromedial nucleus, and sensory cortex. The Japanese Journal of Pharmacology 32(5),767-74.

Biswas, K., Peterkin, T.A., Bryan, M.C., Arik, L., Lehto, S.G., Sun, H., Hsieh, F.Y., Xu, C., Fremeau, R.T., Allen, J.R., 2011. Discovery of potent, orally bio available phthalazinone bradykinin B1 receptor antagonists. Journal of Medicinal Chemistry 54(20), 7232-7246.

Carling, R.W., Moore, K.W., Street L.J., et al., 2004. 3-Phenyl-6(2pyridyl) methyloxy-1,2,4-triazolo[3,4-a]phthalazines and Analogues: high-affinity $\gamma$-aminobutyric acid-a benzodiazepine receptor ligands with $\alpha 2$, $\alpha 3$, and $\alpha 5$ subtypebindingselectivity over $\alpha 1$. Journal of Medicinal Chemistry 47(7), 1807-1822.

Cho, J.Y., Kwon, H.C., Williams, P.G., Jensen, P.R., Fenical, W., 2006. Azamerone, a terpenoid phthalazinone from a marine-derived bacterium related to the genus Streptomyces (Actinomycetales). Organic Letters 8(12), 2471-2474.

Choi, Y.J., Kim, H., Kim, J.W., Song, C.W., Kim, D.S., Yoon, S., Park, H.J. 2018. Phthalazinone Pyrazole Enhances the Hepatic Functions of Human Embryonic Stem CellDerived Hepatocyte-Like Cells via Suppression of the Epithelial-Mesenchymal Transition. Stem Cell Reviews 14(3), 438-450.

Cockcroft, X.L., Dillon, K.J., Dixon, L., Drzewiecki, J., Kerrigan, F., Loh, V.M.Jr., Martin, N.M., Menear, K.A., Smith, G.C., 2006. Phthalazinones 2: Optimisation and synthesis of novel potent inhibitors of poly(ADP-ribose)polymerase. Bioorganic and Medicinal Chemistry Letters 16(4), 10401044.

Coelho, E., Sotelo, N., Fraizetal., 2004. Pyridazines. Part 36: synthesis and antiplatelet activity of 5- substituted-6-
phenyl-3(2H)pyridazinones. Bioorganic and Medicinal Chemistry Letters 14(2), 321-324.

del Olmo, E., Barboza, B., Ybarra, M.I., López-Pérez, J.L., Carrón, R., Sevilla, M.A., Boselli, C., San Feliciano, A., 2006. Vasorelaxant activity of phthalazinones and related compounds. Bioorganic and Medicinal Chemistry Letters 16(10), 2786-2790.

Demirayak, S., Karaburun, A.C., Beis, R.. 2004. Some pyrrole substituted aryl pyridazinone and phthalazinone derivatives and their anti-hypertensive activities. European Journal of Medicinal Chemistry 39(12), 10891095.

Demirayak, S., Karaburun, A.C., Kayagil, I., Erol, K., Sirmagul, B., 2004 Some pyridazinone and phthalazinone derivatives and their vasodilator activities. Archives of Pharmacal Research 27(1), 13-18.

Derita, M., Del Olmo, E., Barboza, B., García-Cadenas, A.E., López-Pérez, J.L., Andújar, S., Enriz, D., Zacchino, S., San Feliciano, A., 2013. Synthesis, bioevaluation and structural study of substituted phthalazin-1(2H)-ones acting as antifungal agents. Molecules 18(3), 3479-501.

Dogruer, D.S., Kupeli, E., Yesilada, E., Sahin, M.F., 2004. Synthesis of new 2-[1(2H)-phthalazinon-2-yl]-acetamide and 3-[1(2H) phthalazinon-2-yl]-propanamide derivatives as antinociceptive and anti-inflammatory agents. Archiv der Pharmazie 337(6), 303-310.

Eguchi, Y., Sugimoto, A., Ishikawa, M., 1980. Studies on antiatherosclerotic agents. VII. Synthesis and structureactivity relationship of 4-hydroxymethyl-1(2H)phthalazinone derivatives. Chemical and Pharmaceutical Bulletin 28(9), 2763-2769.

Elagawany, M., Ibrahim, M.A., Ali Ahmed, H.E., El-Etrawy, A.S.H., Ghiaty, A., Abdel-Samii, Z.K., El-Feky, S.A., Bajorath, J., 2013. Design, synthesis, and molecular modelling of pyridazinone and phthalazinone derivatives as protein kinases inhibitors. Bioorganic and Medicinal Chemistry Letters 23(7), 2007-2013.

Furuta, Y., Takahira, T., Ueno, M., 1985. Effects of 7ethoxycarbonyl-4-hydroxymethyl-6,8-dimethyl-1(2H)phthalazinone (EG 626), a new phosphodiesterase inhibitor, on the cardiovascular system of the dog. Arzneimittelforschung 35(5), 827-832.

Groves, B.M., Rubin, L.J., Frosolono, M.F., 1985. A comparison of the acute hemo dynamic effects of prostacyclin and hydralazine in primary pulmonary hypertension. American Heart Journal 110(6), 1200-1204.

Hameed. A.D., Ovais, S., Yaseen, R., Rathore, P., Samim, M., Singh, S., Sharma, K., Akhtar, M., Javed, K., 2016. Synthesis and Biological Evaluation of New Phthalazinone Derivatives as Anti-Inflammatory and Anti-Proliferative Agents. Arch Pharm (Weinheim) 349(2), 150-159.

Harada, Y., Tanaka, K., Katori, M., 1979. Non-specific antagonism against thromboxane A2 of 7ethoxycarbonyl-6,8-dimethyl-4-hydroxymethyl-1(2H)phthalazinone (EG-626) in contraction of isolated smooth muscles. Prostaglandins 17(6), 957-966. 
Hasabelnaby, S., Mohi El-Deen, E.M., Goudah, A., 2015. Novel 4-aryl-2(1H)-phthalazinone derivatives as cyclo oxygenase-2 inhibitors: Synthesis, molecular modeling study and evaluation as promising anti-inflammatory agents. Medicinal Chemistry 14(3), 148-163.

Imamura, Y., Noda, A., Imamura, T., Ono, Y., Okawara, T., Noda, $H_{\text {., }}$ 2003. A novel methylthio metabolite of striazolo [3,4a] phthalazine, a lead compound for the development of antianxiety drugs, in rats. Life Sciences 74(1), 29-36.

Inoue, K., Urushibara, K., Kanai, M., Yura, K., Fujii, S., IshigamiYuasa, M., Hashimoto, Y., Mori, S., Kawachi, E., Matsumura, M., Hirano, T., Kagechika, H., Tanatani, A., 2015. Design and synthesis of 4-benzyl-1-(2H)phthalazinone derivatives as novel androgen receptor antagonists. European Journal of Medicinal Chemistry 102, 310-319.

Inoue, Y., 1983. Experimental study on an antihypersensitivity agent, 4-(p-chlorobenzyl)-2-[Nmethyl-perhydroazepinyl-(4)]-1-(2H) phthalazinone hydrochloride (azelastine). Nihon Ika Daigaku Zasshi 50(3), 371-378.

Ishikawa, M., Eguchi, Y., Sugimoto, A., 1980. Studies on antiatherosclerotic agents. IX. Synthesis of 7ethoxycarbonyl-4-hydroxymethyl-6,8-dimethyl-1(2H)phthalazinone (EG626). Chemical and Pharmaceutical Bulletin 28(9), 2770-2778.

Johnson CR, Gorla SK, Kavitha M, Zhang M, Liu X, Striepen B, Mead JR, Cuny GD, Hedstrom L., 2013. Phthalazinone inhibitors of inosine-5'-monophosphate dehydrogenase from Cryptosporidium parvum. Bioorganic and Medicinal Chemistry Letters 23(4), 10041007.

Kagayama, K., Morimoto, T., Nagata, S., Katoh, F., Zhang, X., Inoue, N., Hashino, A., Kageyama, K., Shikaura, J., Niwa, T., 2009. Synthesis and biological evaluation of novel phthalazinone derivatives as topically active phosphodiesterase 4 inhibitors. Bioorganic and Medicinal Chemistry 17(19), 6959-6970.

Kassem, E.M., Kamel, M.M., Makhlouf, A.A., Omar, M.T., 1989. New 4-substituted phthalazinone derivatives with possible antibacterial activity. Pharmazie 44(1), 62-63.

Keller, C.A., Shepard, Jr, J.W., Chun, D.S., 1984. Effects of hydralazine on hemodynamics, ventilation, and gas exchange in patients with chronic obstructive pulmonary disease and pulmonary hypertension. The American Review of Respiratory Disease 130(4), 606-611.

Khalil, N.A., Ahmed, E.M., Elshihawy, H.A., Zaitone, S.A., 2013. Novel 4-substituted-2(1H)-phthalazinone derivatives: synthesis, molecular modeling study and their effects on $\alpha$-receptors. Archives of Pharmacal Research 36(6), 671683.

Kietzmann, M., Lubach, D., Molliere, M., Szelenyi, I., 1992. Effects of the phthalazinone azelastine on epidermal metabolism after mechanical skin irritation. Pharmacology 45(5), 269-277.
Kim, J.S., Lee, H.-J., Suhetal, M.-E., 2004. Synthesis and cytotoxicity of 1-substituted 2-methyl-1H-imidazo[4,5g]phthalazine-4,9-dione derivatives. Bioorganic and Medicinal Chemistry 12(13), 3683-3686.

LZhu, Y., Shui, M., Zhou, T., Cai, Y., Wang, W., Xu, F., Niu, Y., Wang, C., Zhang, J.L., Xu, P., Yuan, L., Liang, L., 2016. Rational Design of Fluorescent Phthalazinone Derivatives for One- and Two-Photon Imaging. Chemistry 22(35), 12363-12370.

Lebsack, A.D., Gunzner, J., Wang, B., et al., 2004. Identification and synthesis of $[1,2,4]$ triazolo[3,4-a]phthalazine derivatives as high-affinity ligands to the $\alpha 2 \delta-1$ subunit of voltage gated calcium channel. Bioorganic \& Medicinal Chemistry Letters 14(10), 2463-2467.

Lu, D., Liu, J., Zhang, Y., Liu, F., Zeng, L., Peng, R., Yang, L., Ying, H., Tang, W., Chen, W., Zuo, J., Tong, X., Liu, T., Hu, Y.,2018. Discovery and optimization of phthalazinone derivatives as a new class of potent dengue virus inhibitors. European Journal of Medicinal Chemistry 145, 328-337.

Madhavan, G.R., Chakrabarti, R., Kumar, S.K., Misra, P., Mamidi, R.N., Balraju, V., Kasiram, K., Babu, R.K., Suresh, J., Lohray, B.B., Lohrayb, V.B., Iqbal, J., Rajagopalan, R., 2001. Novel phthalazinone and benzoxazinone containing thiazolidinediones as antidiabetic and hypolipidemic agents. European Journal of Medicinal Chemistry 36(7-8), 627-637.

Marzouk, M.I., Shaker, S.A., Abdel Hafiz, A.A., El-Baghdady, K.Z., 2016. Design and synthesis of new phthalazinone derivatives containing benzyl moiety with anticipated antitumor activity. Biological and Pharmaceutical Bulletin 39(2), 239-251.

Mavel, S., Thery, L., Gueiffier, A., 2002. Synthesis of imidazo [2, 1-a] phthalazines, potential inhibitors of p38 MAP kinase. Prediction of binding affinities of protein ligands. Archiv der Pharmazie 335(1), 7-14.

Mood, A.D., Premachandra, I.D., Hiew, S., Wang, F., Scott K.A., Oldenhuis, N.J., Liu, H., Van Vranken, D.L. 2017. Potent Antifungal Synergy of Phthalazinone and Isoquinolones with Azoles Against Candida albicans. ACS Medicinal Chemistry Letters 8(2), 168-173.

Prime, M.E., Courtney, S.M., Brookfield, F.A., Marston, R.W., Walker, V., Warne, J., Boyd, A.E., Kairies, N.A., von der Saal, W., Limberg, A., Georges, G., Engh, R.A., Goller, B., Rueger, P., Rueth, M., 2011. Phthalazinone pyrazoles as potent, selective, and orally bioavailable inhibitors of Aurora-A kinase. Journal of Medicinal Chemistry 54(1), 312-319. .

Procopiou, P.A., Browning, C., Buckley, J.M., Clark, K.L., Fechner, L., Gore, P.M., Hancock, A.P., Hodgson, S.T., Holmes, D.S., Kranz, M., Looker, B.E., Morriss, K.M., Parton, D.L., Russell, L.J., Slack, R.J., Sollis, S.L., Vile, S., Watts, C.J., 2011. The discovery of phthalazinonebased human $\mathrm{H} 1$ and $\mathrm{H} 3$ single-ligand antagonists suitable for intranasal administration for the treatment of allergic rhinitis. Journal of Medicinal Chemistry 54(7), 2183-2195. 
Procopiou, P.A., Browning, C., Gore, P.M., Lynn, S.M., Richards, S.A., Slack, R.J., Sollis, S.L., 2012. Synthesis and pharmacological investigation of azaphthalazinone human histamine $\mathrm{H}(1)$ receptor antagonists. Bioorganic \& Medicinal Chemistry 20(20), 6097-6108.

Procopiou, P.A., Ford, A.J., Gore, P.M., Looker, B.E., Hodgson, S.T., Holmes, D.S., Vile, S., Clark, K.L., Saunders, K.A., Slack, R.J., Rowedder, J.E., Watts, $\quad$ C.J., $\quad 2017 . \quad$ Design of Phthalazinone Amide Histamine $\quad \mathrm{H}_{1}$ Receptor Antagonists for Use in Rhinitis. ACS Medicinal Chemistry Letters 8(5), 577-581.

Qin, P., Hong, X., Karim, M.N., Shintani, T., Li, J., Chen, C., 2013. Preparation of poly(phthalazinone-ether-sulfone) sponge-like ultrafiltration membrane. Langmuir 29(12), 4167-4175.

Rao, D.S., Rao, V.L., Subbaiah, T., 2016. Synthesis, characterisation, and biological activity of novel pthalazine derivatives. World Journal of Pharmaceutical Sciences 5(6), 2455-2465.

Shigenobu, K., Iwayama, Y., Sakai, R., Kasuya, Y., 1980. Cardiotonic effect of phthalazinol (EG-626) in the isolated guinea pig by myocardium: mechanical and electrophysiological study. Journal of Pharmacobiodynamics 3(10), 543-552.

Shu, Y., Yi, Y., Huo, J., Liu, N., Wang, K., Lu, Y., Wang, X., Wu, Z., Shu, Y., Zhang, S., 2017. Interactions between poly(phthalazinone ether sulfone ketone) (PPESK) and TNT or TATB in polymer bonded explosives: a molecular dynamic simulation study. Journal of Molecular Modeling 23(12), 334.

Sivakumar, R., Gnanasam, S.K., Ramachandran, S., Leonard, J.T., 2002. Pharmacological evaluation of some new 1substituted-4-hydroxyphthalazines. European Journal of Medicinal Chemistry 37, 793-801.

Sonmez, M., Berber, I., Akbas, E., 2006.Synthesis, antibacterial and antifungal activity of some new pyridazinone metal complexes. European Journal of Medicinal Chemistry 41(1), 101-105.

Sugimoto, A., Sakamoto, K., Fujino, Y., Takashima, Y., Ishikawa, M. 1985. Synthesis and inhibitory effect on platelet aggregation of 2-phenyl-1 $(2 \mathrm{H})$-phthalazinone derivatives. Chemical and Pharmaceutical Bulletin 33(7), 2809-2820.

Sugimoto, A., Tanaka, H., Eguchi, Y., Ito, S., Takashima, Y., Ishikawa, M., 1984. 7-(Ethoxycarbonyl)-6,8-dimethyl2-phenyl-1(2H)-phthalazinone derivatives: synthesis and inhibitory effects on platelet aggregation. Journal of Medicinal Chemistry 27(10), 1300-1305.

Sutherland, J.B., Heinze, T.M., Schnackenberg, L.K., Freeman, J.P., Williams, A.J., 2011. Biotransformation of quinazoline and phthalazine by Aspergillus niger. Journal of Bioscience and Bioengineering 111(3), 333-335.

Tanaka, K., Harada, Y., Iwata, M., Katori, $\quad$ M., 1980. Potentiation of anti-aggregating activity of PGI2 by 7 ethoxycarbonyl-6,8-dimethyl-4-hydroxymethyl-1(2H)phthalazinone (EG-626) in rabbit platelets in vitro. Prostaglandins 20(2), 255-68.
Tanizaki, Y., Ohtani, J., Kimura, I., 1992. Actions and crossreactivity of antiallergic agents and a calcium channel antagonist on rat peritoneal mast cells. Difference in the action mechanisms and cross-reactivity among the agents. Agents and Actions 37(1-2), 8-15.

Tasaka, K., Akagi, M., 1979. Anti-allergic properties of a new histamine antagonist, 4-(p-chlorobenzyl)-2-[N-methylperhydroazepinyl-(4)]-1-(2H) one hydrochloride Arzneimittelforschung 29(3), 488-493.

Tatsumi, K., Ou, T., Yamada, H., Yoshimura, H., 1980. Studies of metabolic fate of a new antiallergic agent, azelastine (4-(p-chlorobenzyl)-2-[N-methylperhydroazepinyl-(4)]$1-(2 \mathrm{H})$ phthalazin-one hydrochloride). The Japanese Journal of Pharmacology 30(1), 37-48.

Tsoungas, P.G., Searcey, M., 2001. A convenient access to benzo-substituted phthalazines as potential precursors to DNA intercalators. Tetrahedron Letters 42, 65896592.

Tsoungas, P.G., Searcey, M., 2001. Aconvenient access to benzosubstituted phthalazines as potential precursors to DNA intercalators. Tetrahedron Letters 42(37), 65896592.

Turk, C., Svete, J., Stanovnik, B., et al., 2001. Regioselective1,3dipolar cycloadditions of (1Z)-1-(arylmethylidene)-5,5dimethyl-3oxopyrazolidin-1-ium-2-ide azomethine imines to acetylenic dipolarophiles. Helvetica Chimica Acta 84(1), 146-156.

Van der Mey, M., Hatzelmann, A., Van der Laan, I.J., Sterk, G.J., Thibaut, U., Timmerman, H., 2001. Novel selective PDE4 inhibitors. 1. Synthesis, structure-activity relationships, and molecular modeling of 4-(3,4dimethoxyphenyl)-2H-phthalazin-1-ones and analogues. Journal of Medicinal Chemistry 44(16), 2511-2522.

Wang, H., Cai, J., Huang, H., Deng, G.J., 2014. Palladiumcatalyzed phthalazinone synthesis using paraformaldehyde as carbon source. Organic Letters 16(20), 5324-5327.

Wang, W., Feng, X., Liu, H.X., Chen, S.W., Hui, L., 2018. Synthesis and biological evaluation of 2,4-disubstituted phthalazinones as Aurora kinase inhibitors. Bioorganic \& Medicinal Chemistry S0968-0896(18), 30621-30627.

Yamaguchi, M., Kamei, K., Koga, T., Akima, M., Kuroki, T., Ohi, N., 1993. Novel antiasthmatic agents with dual activities of thromboxane A2 synthetase inhibition and bronchodilation. 1. 2-[2-(1-Imidazolyl) alkyl]-1(2H)phthalazinones. Journal of Medicinal Chemistry 36(25), 4052-4060.

Yamaguchi, M., Kamei, K., Koga, T., Akima, M., Maruyama, A., Kuroki, T., Ohi, N., 1993. Novel antiasthmatic agents with dual activities of thromboxane A2 synthetase inhibition and bronchodilation. 2. 4-(3-Pyridyl)-1(2H)phthalazinones. Journal of Medicinal Chemistry 36(25), 4061-4068.

Yang, L., Wang, W., Sun, Q., Xu, F., Niu, Y., Wang, C., Liang, L., $\mathrm{Xu}, \mathrm{P} ., 2$ 2016. Development of novel proteasome 
inhibitors based on phthalazinone scaffold. Bioorganic and Medicinal Chemistry Letters 26(12), 2801-2805.

Yuan, K., Liu, C., Zong, L., Yu, G., Cheng, S., Wang, J., Weng, Z., Jian, X., 2017. Promoting and Tuning Porosity of Flexible Ether-Linked Phthalazinone-Based Covalent Triazine Frameworks Utilizing Substitution Effect for Effective $\mathrm{CO}_{2}$ Capture. ACS Applied Materials \& Interfaces 9(15), 13201-13212.

Visit us at: http://bosaljournals.com/chemint/

Submissions are accepted at: editorci@bosaljournals.com 